\title{
Can Psychological, Social and Demographical Factors Predict Clinical Characteristics Symptomatology of Bipolar Affective Disorder and Schizophrenia?
}

\author{
Malgorzata Maciukiewicz ${ }^{1,2,3} \cdot$ Joanna Pawlak $^{1} \cdot$ \\ Pawel Kapelski ${ }^{1} \cdot$ Magdalena Labędzka $^{1} \cdot$ Maria Skibinska $^{1}$ • \\ Dorota Zaremba $^{1}$ • Anna Leszczynska-Rodziewicz ${ }^{1}$ • \\ Monika Dmitrzak-Weglarz ${ }^{1} \cdot$ Joanna Hauser $^{1}$
}

Published online: 8 December 2015

(c) The Author(s) 2015. This article is published with open access at Springerlink.com

\begin{abstract}
Schizophrenia (SCH) is a complex, psychiatric disorder affecting $1 \%$ of population. Its clinical phenotype is heterogeneous with delusions, hallucinations, depression, disorganized behaviour and negative symptoms. Bipolar affective disorder (BD) refers to periodic changes in mood and activity from depression to mania. It affects $0.5-1.5 \%$ of population. Two types of disorder (type I and type II) are distinguished by severity of mania episodes. In our analysis, we aimed to check if clinical and demographical characteristics of the sample are predictors of symptom dimensions occurrence in BD and SCH cases. We included total sample of 443 bipolar and 439 schizophrenia patients. Diagnosis was based on DSM-IV criteria using Structured Clinical Interview for DSM-IV. We applied regression models to analyse associations between clinical and demographical traits from OPCRIT and symptom dimensions. We used previously computed dimensions of schizophrenia and bipolar affective disorder as quantitative traits for regression models. Male gender seemed protective factor for depression dimension in schizophrenia and bipolar disorder sample. Presence of definite psychosocial stressor prior disease seemed risk factor for depressive and suicidal domain in BD and SCH. OPCRIT items describing premorbid functioning seemed related with depression, positive and disorganised dimensions in schizophrenia and psychotic in BD. We proved clinical and demographical characteristics of the sample are predictors of symptom dimensions of schizophrenia and bipolar disorder. We also saw relation between clinical dimensions and course of disorder and impairment during disorder.
\end{abstract}

Keywords Schizophrenia $\cdot$ Bipolar affective disorder $\cdot$ OPCRIT $\cdot$ Dimensions

Joanna Pawlak

joanna.pawlak@gmail.com

1 Laboratory of Psychiatric Genetics, Department of Psychiatry, Poznan University of Medical Sciences, Rokietnicka St. 8, 60-806 Poznan, Poland

2 Pharmacogenetics Research Clinic, Campbell Family Mental Health Research Institute, Centre for Addiction and Mental Health, Toronto, ON, Canada

3 Department of Psychiatry, University of Toronto, Toronto, ON, Canada 


\section{Background}

Schizophrenia $(\mathrm{SCH})$ is a complex, psychiatric disorder with a mean lifetime morbid risk $1 \%$ [1]. Its clinical phenotype is heterogeneous with delusions, hallucinations, depression, bizarre or disorganized behaviour and negative symptoms. Depressive episodes are also observed during SCH course [2]. Schizophrenia is influenced by both genetic and environmental factors [3]. Its exact etiology is still undescribed, thus Riley [4] suggested it is rather genetically mediated than genetically determined $(\mathrm{H}=0.8)$. There are several environmental risk factors of schizophrenia, including: premature birth and low birth weight [5], maternal infections during pregnancy [6], hypoxia during neurodevelopment [7], seasonality of birth [8]. There are also psychological risk factors, including family instability and trauma during childhood [9].

Bipolar affective disorder (BD) refers to periodic changes in mood and activity from depression to mania. It affects $1 \%$ of population. Two types of disorder (type I and type II) are distinguished by severity of mania episodes [10]. Mixed states are also observed. Psychotic symptoms are observed in some cases [11]. Family history of bipolar disorder is important risk factor [12]. As in schizophrenia, environmental risk factors of disorder are known. Dysfunctional interactions among family members increase the risk [13].

Schizophrenia and BD are both complex in terms of both clinical and genetic picture. Thus many factor analysis studies aimed to find clinical dimensions. Depressive, positive, negative, excitement and disorganised domains were detected in $\mathrm{SCH}$ sample, whereas depressive, excitement and psychotic appeared for BD [14-18]. Potentially useful strategy is to use previously computed factor structure to seek for association with pre-morbid risk factors [15].

Both disorders (SCH and BD) are characterised by substantial genetic overlap. The genetic correlation coefficient equalled 0.6. Results from twin and adoption studies suggests overlap with schizoaffective disorder as well [19]. The large clinical overlap between schizophrenia and bipolar affective disorder is also known [20, 21].

In our study, we investigated if clinical and demographical characteristics of the sample (e.g. age at onset, duration of illness, sex) are predictors of symptom dimensions. Clinical dimensions describe disorder diversity and severity. We analysed if/how socio-demographical and clinical characteristics influence symptomatology of SCH and BD. To achieve our goal, we applied previously computed factor structure [14] as quantitative trait for regression models.

\section{Sample Analysed}

The sample comprised 892 bipolar disorder $(n=443)$ and schizophrenia $(n=449)$ patients. Diagnosis was based on DSM-IV criteria using Structured Clinical Interview for DSM-IV (SCID) [22]. We collected data about familial burden of the psychiatric disorders where possible. Lifetime perspective of symptoms was based on OPCRIT [23] checklist.

The average age at onset of $\mathrm{BD}$ individuals was 30.62 ( $\mathrm{SD}=11.17)$, whereas in schizophrenia cases $23.4(\mathrm{SD}=6.59)$. Longer duration of illness appeared for $\mathrm{SCH}$ patients $(22.25 ; \mathrm{SD}=21)$ in comparison with BD ones $(19.37 ; \mathrm{SD}=14.83)$. Majority of patients were employed before onset of disorder (53\% in $\mathrm{SCH}$ and $83 \%$ in $\mathrm{BD}$ ). 
All subjects were inpatients from Wielkopolska region of Poland. Patients gave written consent for the study after being informed about its details. Local Bioethics Committee approved the study. Sample characteristics is depicted in the Table 1.

\section{Statistical Analysis}

We applied Poisson regression models to detect relations between symptom dimensions and social/demographic characteristics. Previously described dimensions worked as quantitative dependent variable [14], thus we used Poisson instead of logistic regression. We defined quantitative trait (symptom dimension) as a sum of appropriate OPCRIT ratings. Item composition of particular domains is shown in Table 2 . The high score of dimension (for example depressive) means, that most items generating domain ratings exceeding 0 . It is not identical with severe depression identified by clinical terms.

Table 1 Sample characteristics. NA's ("not available") refers to situation when there are absences in OPCRIT items

\begin{tabular}{|c|c|c|}
\hline & Schizophrenia $(\mathrm{n}=439)$ & $\begin{array}{l}\text { Bipolar affective disorder }(n= \\
443)\end{array}$ \\
\hline Sex & $\begin{array}{l}\text { Female: } 224(51 \%) \\
\text { Male: } 215(49 \%)\end{array}$ & $\begin{array}{l}\text { Female: } 252(57 \%) \\
\text { Male: } 191(43 \%)\end{array}$ \\
\hline Age at onset & $\begin{array}{l}\text { Mean: } 23.08 \\
\text { Min: } 5.0 \\
\text { Max: } 52.0 \\
\text { SD: } 6.59\end{array}$ & $\begin{array}{l}\text { Mean: } 30.62 \\
\text { Min: } 10.0 \\
\text { Max: } 63.0 \\
\text { SD: } 11.17\end{array}$ \\
\hline Family history of schizophrenia & $\begin{array}{l}\text { Absent: } 346(79 \%) \\
\text { Present: } 81(18 \%) \\
\text { NAs: } 12(3 \%)\end{array}$ & $\begin{array}{l}\text { Absent: } 409(93 \%) \\
\text { Present: } 24(5 \%) \\
\text { NAs: } 10(2 \%)\end{array}$ \\
\hline $\begin{array}{l}\text { Family history of other psychiatric } \\
\text { disorders }\end{array}$ & $\begin{array}{l}\text { Absent: } 307(70 \%) \\
\text { Present: } 108(25 \%) \\
\text { NAs: } 12(5 \%)\end{array}$ & $\begin{array}{l}\text { Absent: } 216(49 \%) \\
\text { Present: } 221(50 \%) \\
\text { NAs: } 6(1 \%)\end{array}$ \\
\hline Marital status & $\begin{array}{l}\text { Married: } 107(24 \%) \\
\text { Single: } 330(75.8 \%) \\
\text { NAs: } 2(0.2 \%)\end{array}$ & $\begin{array}{l}\text { Maried: } 307(69 \%) \\
\text { Single: } 135(30 \%) \\
\text { NAs: } 1(1 \%)\end{array}$ \\
\hline Employment status at onsent & $\begin{array}{l}\text { Employed: } 228(52 \%) \\
\text { Unemployed: } 198 \\
\quad(45 \%) \\
\text { NAs: } 13(3 \%)\end{array}$ & $\begin{array}{l}\text { Employed: } 373(84 \%) \\
\text { Unemployed: } 63(14 \%) \\
\text { NAs: } 7(2 \%)\end{array}$ \\
\hline $\begin{array}{l}\text { Definite psychosocial stressor prior to } \\
\text { onset }\end{array}$ & $\begin{array}{l}\text { Absent: } 338(77 \%) \\
\text { Present: } 89(20 \%) \\
\text { NAs: } 12(3 \%)\end{array}$ & $\begin{array}{l}\text { Absent: } 243(55 \%) \\
\text { Present: } 162(36 \%) \\
\text { NAs: } 33(9 \%)\end{array}$ \\
\hline Average duration of episode in weeks & $\begin{array}{l}\text { Mean: } 20.99 \\
\text { Min: } 1 \\
\text { Max: } 240.00 \\
\text { SD: } 21\end{array}$ & $\begin{array}{l}\text { Mean: } 19.37 \\
\text { Min: } 2 \\
\text { Max: } 156.00 \\
\text { SD: } 14.83\end{array}$ \\
\hline
\end{tabular}


Table 2 Previously described dimensional structure of schizophrenia and bipolar affective disorder [14]

\begin{tabular}{|c|c|c|}
\hline & Dimension & OPCRIT items \\
\hline \multirow[t]{10}{*}{ Schizophrenia } & Depression (main) & $\begin{array}{l}\text { Slowed activity, loss of energy/tiredness, dysphoria, loss of } \\
\text { pleasure, altered libido, suicidal ideation }\end{array}$ \\
\hline & $\begin{array}{l}\text { Appetite } \\
\text { disturbances }\end{array}$ & Poor appetite, weight loss \\
\hline & Suicidal & Excessive self reproach, delusions of guilt, nihilistic delusions \\
\hline & Excitment & $\begin{array}{l}\text { Excessive activity, reckless activity, distractibility, reduced need } \\
\text { for sleep, agitated activity, pressured speech, thoughts racing, } \\
\text { elevated mood, increased sociability }\end{array}$ \\
\hline & Atypical depression & Increased appetite, weight gain \\
\hline & Disorganised & $\begin{array}{l}\text { Speech difficult to understand, incoherent, positive formal thought } \\
\text { disorder, inappropriate affect }\end{array}$ \\
\hline & Negative & Restricted affect, blunted affect \\
\hline & Psychotic & $\begin{array}{l}\text { Relationship between psychotic and affective symptoms, } \\
\text { widespread delusions, primary delusions perception, other } \\
\text { primary delusions }\end{array}$ \\
\hline & $\begin{array}{l}\text { Positive (first rank } \\
\text { symptoms) } 1\end{array}$ & $\begin{array}{l}\text { Delusions of influence, delusions of passivity, thought insertion, } \\
\text { thought withdrawal, thought broadcast, thought echo }\end{array}$ \\
\hline & $\begin{array}{l}\text { Positive (first rank } \\
\text { symptoms) } 2\end{array}$ & $\begin{array}{l}\text { Delusions and hallucinations last for } 1 \text { week, persecutory/jealous } \\
\text { delusions and hallucinations, third person auditory } \\
\text { hallucinations, running commentary voices, abusive/accusatory/ } \\
\text { persecutory voices }\end{array}$ \\
\hline \multirow[t]{6}{*}{$\begin{array}{l}\text { Bipolar } \\
\text { affective } \\
\text { disorder }\end{array}$} & Depression (main) & $\begin{array}{l}\text { Slowed activity, loss of energy/tiredness, dysphoria, diurnal } \\
\text { variation, loss of pleasure, altered libido, poor concentration, } \\
\text { excessive self reproach, suicidal ideation }\end{array}$ \\
\hline & $\begin{array}{l}\text { Appetite } \\
\text { disturbances }\end{array}$ & Poor appetite, weight loss \\
\hline & Atypical depression & Increased appetite, weight gain, excessive sleep \\
\hline & Sleep disturbances & $\begin{array}{l}\text { Middle insomnia (broken sleep), early morning waking, poor } \\
\text { appetite }\end{array}$ \\
\hline & Psychotic & $\begin{array}{l}\text { Relationship between psychotic and affective symptoms, } \\
\text { persecutory delusions, grandiose delusions, widespread } \\
\text { delusions }\end{array}$ \\
\hline & Excitement & $\begin{array}{l}\text { Excessive activity, reckless activity, distractibility, reduced need } \\
\text { for sleep, pressured speech, thoughts racing, elevated mood }\end{array}$ \\
\hline
\end{tabular}

For BD, we built five models, basing on information collected: (1) affective disorders in a family, bipolar disorder in the family and other disorders in a family (first and second degree relatives); (2) premorbid personality disorder, marital status, employment at onset, work adjustment, premorbid social adjustment and definite psychological stressor prior onset; (3) age at onset: early (childhood and adolescence) and late (adulthood) and sex. Similar to Goldstein, we treated onset when 19 and more as adulthood and called it late [24]. In case of schizophrenia sample we checked following models: (1) gender and age at onset. Schizophrenia, as other neuropsychiatric illnesses, starts typically in late adolescence [25]. Thus, we treated age at onset 18 and earlier as early and onset later than 19 as late; (2) premorbid personality disorder, marital status, employment at onset, poor work 
adjustment, premorbid social adjustment and definite psychological stressor prior onset; (3) family history of schizophrenia, family history of other psychiatric disorders.

At the final stage, we used clinical dimension to predict course and impairment/incapacity during illness. Course of disorder and impairment/incapacity during disorder are measured by OPCRIT variables. Course (scored 1-5) is described as: single episode with good recovery (1); multiple episodes with good recovery (2); multiple episodes with partial recovery (3); continuous chronic illness (4); continuous chronic illness with deterioration (5). When impairment/incapacity is measured (scored 0-3) it is reported as: no impairment (0); subjective impairment at work, school, or in social functioning (1); impairment in major life role with definite reduction in productivity and/or criticism has been received (2); no function at all in major life role for more than 2 days, or in patient treatment has been required or active psychotic symptoms such as delusions or hallucinations have occurred (3).

All computations were performed using R environment [26].

\section{Results}

\section{Regression Models of Bipolar Sample}

We got statistically significant models for depression and psychotic domains. Results are presented in Table 3.

For depression domain, significant results appeared for models: (1) gender + age at onset; (2) premorbid personality disorder + marital status + employment at onset + work adjustment, premorbid social adjustment + definite psychological stressor prior onset. Male gender seemed protective factor for depression dimension ( $p=0.004$; OR 0.931). Presence of psychosocial stressor prior disease onset appeared as risk factor $(p=0.006$; OR 1.072) for depression scores.

The same models (1) and (2) gave statistically important results for psychotic dimension. Late age at onset decreases its $\operatorname{scores}(p=0.005$; OR 0.783). Being unemployed before disease onset $(p=0.0008$; OR 1.375) and having marital status "single" $(p=0.0047$; OR 1.254) were risk factors.

\section{Regression Models of Schizophrenia}

For schizophrenia sample, we got statistically significant models for depression, positive, disorganised and excitement dimensions (see Table 2). We got strongest results for two models: (1) gender + age at onset and (2) premorbid personality disorder + marital status + employment at onset + work adjustment, premorbid social adjustment + definite psychological stressor prior onset.

Male gender ( $p=0.016$; OR 0.922) and late age at onset ( $p=0.0$; OR 0.745) seemed protective towards depressive dimension. Presence of premorbid personality disorder $(p=0.0006$; OR 1.275) is a risk factor for higher depression scores. Absence of poor premorbid social adjustment decreases main depressive $(p=0.006$; OR 0.904) and disorganization ( $p=0.0097$; OR 0.839) domains scores. Presence of psychiatric disorders in family seemed risk factor for depressive dimension $\left(p=2.28 \times 10^{-5}\right.$; OR 1.174). "Marital status" equalled "single" increased depression scores ( $p=0.04$; OR 1.094). We detected presence of psychological stressor prior to disorder onset ( $p=0.003$; OR 1.490) 


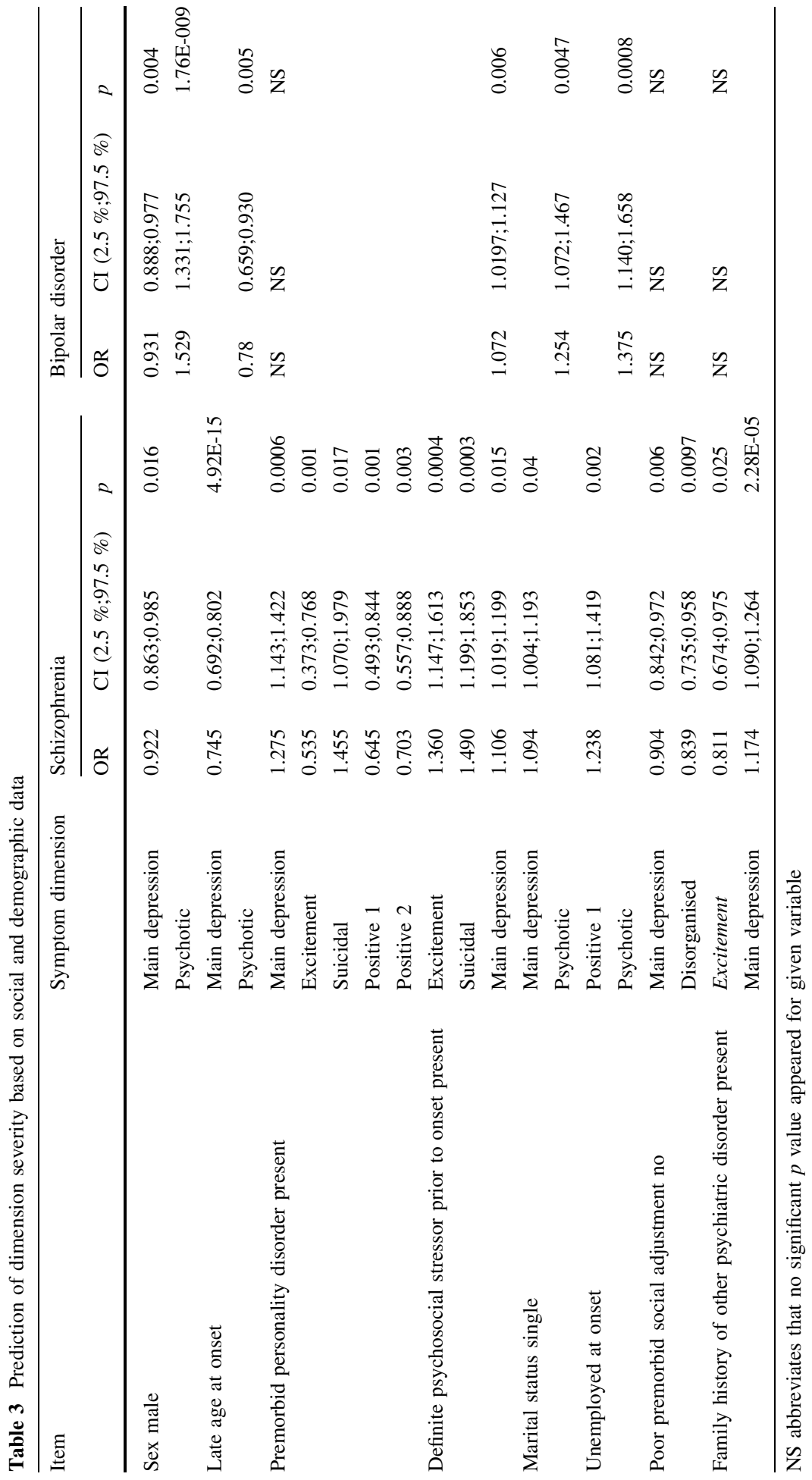


and premorbid personality disorder ( $p=0.017$; OR 1.455$)$ as increasing suicidal dimension scores.

Presence of premorbid personality disorder diminishes excitement dimension scores ( $p=0.001$; OR 0.535). When premorbid psychological stressor prior to disease onset appeared, it increases excitement domain scores $(p=0.002$, OR 1.023). Family history of other psychiatric disorder seemed protective towards schizophrenia's excitement dimension scores $(p=0.025$, OR 0.811).

Two positive psychotic subdimensions (described as positive 1 and positive 2) were related to premorbid functioning traits, i.e. presence of premorbid personality disorder and being unemployed at disease onset. Being unemployed seemed risk factor $(p=0.002$, OR 1.238) of positive 1 subdimension. Presence of premorbid personality disorder was protective towards both positive $1(p=0.001$, OR 0.645$)$ and positive 2 dimension ( $p=0.003$; OR 0.703) domains.

\section{Clinical Dimensions as Course Predictors}

We observed relation of main depression dimension of bipolar disorder when use clinical dimensions as independent variables for regression equation. In the schizophrenia sample disorganised and excitement domains seemed important predictors of "impairment/incapacity during disorder" and "course of disorder" defined by OPCRIT checklist (see Table 4).

Main depression domain seemed to increase risk of worse course of bipolar disorder ( $p=0.02$, OR 1.023). Course of disorder is defined by OPCRIT variables and coded numerically. "Worse course" means higher ratings in "course of disorder" item. In the schizophrenia sample, disorganization dimension was related with individual incapacity during disorder. When more disorganization symptoms appeared (higher score of domain), case's incapacity increases $(p=0.034$, OR 1.045). Excitement symptoms decrease $(p=0.01$, OR 0.970) impairment and incapacity during disorder scores.

\section{Discussion}

Previous researchers proved relations between clinical and demographical traits and psychiatric disorders. In our study we use previously computed clinical dimensions of schizophrenia and bipolar disorder to seek for its relation with sample characteristics. We

Table 4 Dimensions and prediction of disorder course and impairment/incapacity during disorders

\begin{tabular}{|c|c|c|c|c|c|c|}
\hline \multirow[t]{2}{*}{ Item } & \multicolumn{3}{|c|}{ Schizophrenia } & \multicolumn{3}{|c|}{ Bipolar disorder } \\
\hline & OR & $\begin{array}{l}\text { CI } \\
(2.5 \% ; 97.5 \%)\end{array}$ & $p$ & OR & $\begin{array}{l}\text { CI } \\
(2.5 \% ; 97.5 \%)\end{array}$ & $p$ \\
\hline Course of disorder & NS & NS & NS & 1.023 & 1.009;1.039 & 0.002 \\
\hline $\begin{array}{l}\text { Impairment incapacity } \\
\text { during disorder }\end{array}$ & $0.970 ; 1.045$ & $\begin{array}{l}0.948 ; 0.993 ; \\
1.003 ; 1.088 \\
\end{array}$ & $0.010 ; \underline{0.034}$ & NS & NS & NS \\
\hline
\end{tabular}

NS abbreviates that no significant model obtained for given variable

Normal values indicated main depression symptom dimension; Bold values indicated suicidal symptom dimension; Italicised values indicated excitement symptom dimension; Underlined values indicated disorganised symptom dimension 
applied regression to detect and estimate relations among clinical dimension and clinical and demographical characteristics. We took no assumptions before conducting analyses. Our results are consistent with previous reports about relation of clinical and demographical characteristics and symptom dimensions of schizophrenia and bipolar disorder Marital status "single", presence of family history of psychiatric disorders and premorbid personality disorders as risk factors for depressive domains higher scores. For suicidal subdimension presence of premorbid personality disorder and definite psychological stressor prior onset increase its scores. Male gender and later age at onset seemed protective towards higher depression scores in both schizophrenia and bipolar disorder. Higher depression scores in BD increase course of disorder scores. The relations between excitement domain and family history of psychiatric disorder, premorbid personality disorders and impairment/incapacity during disorder need further investigations.

Male gender seemed protective factor towards depression dimension high scores in schizophrenia and bipolar disorder samples. The observation is consistent with the fact that depression appears more often in woman and females are more likely to have depressive symptoms than males [27]. Other research groups confirmed female sex as significant predictor of depressive symptoms [28] and definite depression [29, 30]. Study by Rodgers group showed several depression subtypes appearance varies between males and females: anxiety disorders appeared in females with typical subtype, whereas males with severe typical type exhibited less masculine orientation. Severe atypical type associated with alcohol/drug dependence in female sample only [31].

For schizophrenia individuals age at onset as important predictor for depression dimension. Late age at onset seemed protective. Study by Faravelli group showed that risk of depression increase with age, but for females before menopause only [32]. Our results might differ, because we analysed not depressive disorder, but depression dimension in a schizophrenia. Recent study by Yasuda group proved late onset of $\mathrm{SCH}$ is characterised by more depressive symptoms [33]. Study by Emsley showed PANSS scores for depression and anxiety symptoms are more severe in females, first-episode individuals and ones with positive symptoms predominant. Depressive/anxiety scores on the other hand correlated with age, positive scores in PANSS and treatment outcome. Researchers also suggested depressive and anxiety scores presence may predict more favourable treatment outcome [34]. In our models "late age at onset" simply means "adult onset", whereas "early age at onset" equals "adolescent age at onset", which may be the reasons of some dissimilarities between our results and those obtained by other research groups. Our models suggest onset after adolescence is somehow protective towards depression symptoms. Further investigations in more detailed age groups might give more insight.

We found presence/absence of premorbid personality disorder as important predictor factor for depression, positive and excitement dimensions in schizophrenia. Premorbid personality disorder seemed to reduce scores of excitement and positive domains. We called our dimension excitement not (hypo)manic as its composed from items describing symptoms (excessive activity, reckless activity, distractibility, reduced need for sleep, agitated activity, pressured speech, thoughts racing, elevated mood and increase sociability). Possible explanation is presence of variables: "increase sociability" and "excessive activity" in excitement domain. Particular premorbid personality traits were related with specific dimensions: sociopathic traits with disorganization, schizotypal with positive dimension, whereas schizoid with negative dimensions and lesser with positive one. Manic traits were associated with disorganization dimension, negative dimension with schizoid, passive-dependent and schizotypic traits $[35,36]$. As Peralta previously suggested, relation between premorbid personality disorders and schizophrenia dimensions should be 
interpreted in caution. It is often observed than premorbid disorders are diagnosed in retrospective [37]. We interpret our results carefully. Without more in depth analyses of premorbid disorders it is difficult to explain its relation with excitement and positive domains.

Presence of premorbid personality disorders and definite psychological stressor prior onset seemed risk factor of suicidal disturbances higher scores in schizophrenia cases. Suicidal behaviour is observed during schizophrenia and associated with depression. Suicide is important cause of death in schizophrenia: $10 \%$ [38] or as suggested by others $4-5 \%[39,40]$ of schizophrenia patients commit suicide. Hopelessness, depression and greater insight into illness make important risk factor for suicidal behaviour, whereas being unmarried and male gender are associated with lower suicide risk [41-43]. Clinical and demographical characteristics and known as risk or protective factors for suicide attempts. Early age at onset, poor premorbid social adjustment and childlessness in females were suggested as associated with suicide attempts in schizophrenia and affective disorders cases. Authors also stated demographical and clinical risk factors cannot be ignored [44]. Other studies however, showed that marital status, age and education do not influence suicidal ideation [45]. Good premorbid functioning as a single factor did not seem protective [46]. We described relation between presence of premorbid personality disorder and definite psychological stressor prior to disease with depressive symptoms associated with suicidal ideation (excessive self-reproach, delusions of guilt and nihilistic delusions), not suicidal behaviour. Probably interaction analyses of premorbid social adjustment and family burden of suicide attempts might produce more in depth models.

We saw relation between premorbid personality disorders and depression domain. Important aspect of depression in schizophrenia, is possible difficulty to distinguish from negative symptoms [47], which are typically present [48]. Premorbid personal disorders, depressive and negative manifestations might exhibit similar clinical picture. Apathy and lack of emotion are similar in both depressive and negative manifestations [49]. Depressive symptoms may be present in chronic phase and acute schizophrenia episode [34]. The fact that OPCRIT items describing premorbid social functioning increases severity of depressive manifestations only, might be results of difficulty mentioned. Early age at onset is associated with more severe negative symptoms of schizophrenia as [50] suggested. We saw late age at onset being protective towards depressive symptoms. However depressive and negative symptoms partly overlap in schizophrenia [51].

In schizophrenia sample, we observed presence of family history of psychiatric disorders, increases depressive dimension scores and decreases excitement dimension scores. It was described as risk of schizophrenia development [52]. We detected it is especially for depression dimension. Depressive symptoms are common in schizophrenia [51] and appear more frequent when there is family history of depression [53]. In our models "late" age at onset seemed protective towards depressive dimension in schizophrenia. No relation of family history and symptom dimensions appeared for bipolar sample.

In the last stage we checked if/how symptomatology of disease might be useful to predict disorder course and social functioning (described by OPCRIT variables "impairment/incapacity during disorder" and "course of disorder"). Higher scores of depression domain are associated with higher scores in course of disorder in BD sample. In case of schizophrenia, "disorganised" dimension seemed risk factor for worse impairment/incapacity during disorder. Excitement domain in $\mathrm{SCH}$ decrease impairment/incapacity, however this result are to interpret carefully. Correlation between depressive symptoms and performance and interpersonal behaviour was described. Mania symptoms seemed related with interpersonal friction [54]. Our bipolar models suggests association between 
high depression scores and high scores in course of disorder. Higher scores in course of disorder correspond to worse remission Partial remission with residual symptoms often happen in bipolar and unipolar disorder [55, 56]. In bipolar sample subsyndromal residual symptoms are related to last episode [57]. In the schizophrenia cases, "disorganised" dimension lead to poor social functioning during its course. Excitement dimension, however seemed protective. The reason might be excitement/mania domain definition. "Increased sociability", "excessive activity" variables might work protective towards social isolation. Disorganization often present in schizophrenia has negative impact of social functioning. Recent study by Pandina proved clinically positive changes in disorganization symptoms enhances individual's overall functioning [58].

Statistical methods enable researchers to detect and describe relationships. Pandina group applied regression models to analyse clinical symptoms and demographic characteristics influences cognitive improvement in schizophrenia and schizoaffective disorder [58]. Fiedorowicz group proved family history of bipolar disorders influence illness course, by increasing risk of hypomania/mania episodes frequency [59]. Recently Skokou and Gourzis checked how age at onset, sex, habitat, marital status and premorbid personality disorders influence paranoid schizophrenia. They proved urban birth, single status and avoidant personality traits are observed in young patients. Differences were more significant in male group. [60]. Detailed analyses of premorbid personality disorders and familial burden is needed to introduce more detailed models.

We proved clinical and demographical characteristics of the sample are predictors of symptom dimensions of schizophrenia and bipolar disorder. We also saw relation between clinical dimensions and course of disorder and impairment during disorder.

Acknowledgments The study is supported by The National Science Centre, Poland, Grant Nos. NN 402 407339,402467140 and 2011/01/B/NZ5/02795.

\section{Compliance with Ethical Standards}

Conflicts of interest All authors declared no conflicts of interest.

Ethical approval All procedures followed were in accordance with the ethical standards of the responsible committee on human experimentation (institutional and national) and with the Helsinki Declaration of 1975, as revised in 2000 (5).

Informed consent Informed consent was obtained from all patients for being included in the study.

Open Access This article is distributed under the terms of the Creative Commons Attribution 4.0 International License (http://creativecommons.org/licenses/by/4.0/), which permits unrestricted use, distribution, and reproduction in any medium, provided you give appropriate credit to the original author(s) and the source, provide a link to the Creative Commons license, and indicate if changes were made.

\section{References}

1. McGrath J, et al.: Schizophrenia: A concise overview of incidence, prevalence, and mortality. Epidemiologic Reviews 30:67-76, 2008

2. Jager M, et al.: Depression during an acute episode of schizophrenia or schizophreniform disorder and its impact on treatment response. Psychiatry Research 158(3):297-305, 2008

3. Sullivan PF, Kendler KS, Neale MC: Schizophrenia as a complex trait: Evidence from a meta-analysis of twin studies. Archives of General Psychiatry 60(12):1187-1192, 2003

4. Riley B, Kendler KS: Molecular genetic studies of schizophrenia. European Journal of Human Genetics 14(6):669-680, 2006 
5. Kunugi H, Nanko S, Murray RM: Obstetric complications and schizophrenia: Prenatal underdevelopment and subsequent neurodevelopmental impairment. The British Journal of Psychiatry 40:s25-s29, 2001

6. Oskvig DB, et al.: Maternal immune activation by LPS selectively alters specific gene expression profiles of interneuron migration and oxidative stress in the fetus without triggering a fetal immune response. Brain, Behavior, and Immunity 26(4):623-634, 2012

7. Schmidt-Kastner R, et al.: An environmental analysis of genes associated with schizophrenia: Hypoxia and vascular factors as interacting elements in the neurodevelopmental model. Molecular Psychiatry 17(12):1194-1205, 2012

8. Torrey EF, et al.: Birth seasonality in bipolar disorder, schizophrenia, schizoaffective disorder and stillbirths. Schizophrenia Research 21(3):141-149, 1996

9. Husted JA, et al.: Early environmental exposures influence schizophrenia expression even in the presence of strong genetic predisposition. Schizophrenia Research 137(1-3):166-168, 2012

10. Craddock N, Sklar P: Genetics of bipolar disorder: Successful start to a long journey. Trends in Genetics 25(2):99-105, 2009

11. MacQueen GM, Hajek T, Alda M: The phenotypes of bipolar disorder: Relevance for genetic investigations. Molecular Psychiatry 10(9):811-826, 2005

12. Craddock N, Sklar P: Genetics of bipolar disorder. Lancet 381(9878):1654-1662, 2013

13. Ferreira GS, et al.: Dysfunctional family environment in affected versus unaffected offspring of parents with bipolar disorder. Australian and New Zealand Journal of Psychiatry 47(11):1051-1057, 2013

14. Maciukiewicz M, et al.: Analysis of OPCRIT results indicate the presence of a novel 'social functioning' domain and complex structure of other dimensions in the Wielkopolska (Poland) population. Schizophrenia Research 138(2-3):223-232, 2012

15. Allardyce J, et al.: Do symptom dimensions or categorical diagnoses best discriminate between known risk factors for psychosis? Social Psychiatry and Psychiatric Epidemiology 42(6):429-437, 2007

16. Dikeos DG, et al.: Distribution of symptom dimensions across Kraepelinian divisions. British Journal of Psychiatry 189:346-353, 2006

17. Serretti A, Olgiati P: Dimensions of major psychoses: A confirmatory factor analysis of six competing models. Psychiatry Research 127(1-2):101-109, 2004

18. Serretti A, et al.: Major psychoses symptomatology: Factor analysis of 2241 psychotic subjects. European Archives of Psychiatry and Clinical Neuroscience 251(4):193-198, 2001

19. Cardno AG, Owen MJ: Genetic relationships between schizophrenia, bipolar disorder, and schizoaffective disorder. Schizophrenia Bulletin 40(3):504-515, 2014. doi:10.1093/schbul/sbu016

20. Andreassen OA, et al.: Genetic pleiotropy between multiple sclerosis and schizophrenia but not bipolar disorder: Differential involvement of immune-related gene loci. Molecular Psychiatry 40(1):13-17, 2014. doi: $10.1093 / \mathrm{schbul} / \mathrm{sbt} 168$

21. Tamminga CA, et al.: Clinical phenotypes of psychosis in the bipolar-schizophrenia network on intermediate phenotypes (B-SNIP). American Journal of Psychiatry 170(11):1263-1274, 2013

22. First MB: User's Guide for the Structured Clinical Interview for DSM-IV Axis II Personality Disorders: SCID-II. Washington, American Psychiatric Press, p. 91, 1997

23. Craddock M, et al.: Concurrent validity of the OPCRIT diagnostic system. Comparison of OPCRIT diagnoses with consensus best-estimate lifetime diagnoses. British Journal of Psychiatry 169(1):58-63, 1996

24. Goldstein BI, Levitt AJ: Further evidence for a developmental subtype of bipolar disorder defined by age at onset: Results from the national epidemiologic survey on alcohol and related conditions. American Journal of Psychiatry 163(9):1633-1636, 2006

25. Gogtay N, et al.: Age of onset of schizophrenia: Perspectives from structural neuroimaging studies. Schizophrenia Bulletin 37(3):504-513, 2011

26. Team RC: R: A Language and Environment for Statistical Computing. Vienna, R Foundation for Statistical Computing, 2013

27. Craddock N, Forty L: Genetics of affective (mood) disorders. European Journal of Human Genetics 14(6):660-668, 2006

28. Kim E, et al.: A survey of depressive symptoms among South Korean adults after the Korean financial crisis of late 1997: Prevalence and correlates. Annals of Epidemiology 15(2):145-152, 2005

29. Oh DH, et al.: Prevalence and correlates of depressive symptoms in korean adults: Results of a 2009 korean community health survey. Journal of Korean Medical Science 28(1):128-135, 2013

30. St John PD, Montgomery PR: Marital status, partner satisfaction, and depressive symptoms in older men and women. Canadian Journal of Psychiatry 54(7):487-492, 2009 
31. Rodgers S, et al.: Symptom-based subtypes of depression and their psychosocial correlates: A personcentered approach focusing on the influence of sex. Journal of Affective Disorders 156:92-103, 2013. doi:10.1016/j.jad.2013.11.021

32. Faravelli C, et al.: Gender differences in depression and anxiety: The role of age. Psychiatry Research 210(3):1301-1303, 2013

33. Yasuda M, et al.: Clinical features of late-onset schizophrenia in Japan: Comparison with early-onset cases. Psychogeriatrics 13(4):244-249, 2013

34. Emsley RA, et al.: Depressive and anxiety symptoms in patients with schizophrenia and schizophreniform disorder. Journal of Clinical Psychiatry 60(11):747-751, 1999

35. Cuesta MJ, Peralta V, Caro F: Premorbid personality in psychoses. Schizophrenia Bulletin 25(4):801-811, 1999

36. Cuesta MJ, et al.: Premorbid personality and psychopathological dimensions in first-episode psychosis. Schizophrenia Research 58(2-3):273-280, 2002

37. Peralta V, Cuesta MJ, de Leon J: Premorbid personality and positive and negative symptoms in schizophrenia. Acta Psychiatrica Scandinavica 84(4):336-339, 1991

38. Caldwell CB, Gottesman II: Schizophrenics kill themselves too: A review of risk factors for suicide. Schizophrenia Bulletin 16(4):571-589, 1990

39. Carlborg A, et al.: Suicide in schizophrenia. Expert Review of Neurotherapeutics 10(7):1153-1164, 2010

40. Palmer BA, Pankratz VS, Bostwick JM: The lifetime risk of suicide in schizophrenia: A reexamination. Archives of General Psychiatry 62(3):247-253, 2005

41. Kao YC, Liu YP: Suicidal behavior and insight into illness among patients with schizophrenia spectrum disorders. Psychiatric Quarterly 82(3):207-220, 2011

42. Balhara YP, Verma R: Schizophrenia and suicide. East Asian Archives of Psychiatry 22(3):126-133, 2012

43. Gomez-Duran EL, Martin-Fumado C, Hurtado-Ruiz G: Clinical and epidemiological aspects of suicide in patients with schizophrenia. Actas Esp Psiquiatr 40(6):333-345, 2012

44. Muller DJ, et al.: Suicide attempts in schizophrenia and affective disorders with relation to some specific demographical and clinical characteristics. European Psychiatry 20(1):65-69, 2005

45. Montross LP, et al.: Suicidal ideation and suicide attempts among middle-aged and older patients with schizophrenia spectrum disorders and concurrent subsyndromal depression. The Journal of Nervous Mental Disease 196(12):884-890, 2008

46. Restifo K, Harkavy-Friedman JM, Shrout PE: Suicidal behavior in schizophrenia: A test of the demoralization hypothesis. The Journal of Nervous and Mental Disorder 197(3):147-153, 2009

47. Chiappelli J, et al.: Assessment of trait and state aspects of depression in schizophrenia. Schizophrenia Bulletin 40(1):132-142, 2014

48. Silveira C, Marques-Teixeira J, de Bastos-Leite AJ: More than one century of schizophrenia: An evolving perspective. Journal of Nervous and Mental Disorder 200(12):1054-1057, 2012

49. Gozdzik-Zelazny A, Borecki L, Pokorski M: Depressive symptoms in schizophrenic patients. European Journal of Medical Research 16(12):549-552, 2011

50. Bellino S, et al.: Relationships of age at onset with clinical features and cognitive functions in a sample of schizophrenia patients. Journal of Clinical Psychiatry 65(7):908-914, 2004

51. Majadas S, et al.: Prevalence of depression and its relationship with other clinical characteristics in a sample of patients with stable schizophrenia. Comprehensive Psychiatry 53(2):145-151, 2012

52. Mortensen PB, Pedersen MG, Pedersen CB: Psychiatric family history and schizophrenia risk in Denmark: Which mental disorders are relevant? Psychological Medicine 40(2):201-210, 2010

53. Babinkostova Z, Stefanovski B: Family history in patients with schizophrenia and depressive symptoms. Prilozi 32(1):219-228, 2011

54. Morriss R, et al.: Differential effects of depression and mania symptoms on social adjustment: Prospective study in bipolar disorder. Bipolar Disorder 15(1):80-91, 2013

55. Paykel ES: Partial remission, residual symptoms, and relapse in depression. Dialogues in Clinical Neuroscience 10(4):431-437, 2008

56. Vieta E, et al.: Subsyndromal depressive symptoms in patients with bipolar and unipolar disorder during clinical remission. Journal of Affective Disorders 107(1-3):169-174, 2008

57. Kaya E, Aydemir O, Selcuki D: Residual symptoms in bipolar disorder: The effect of the last episode after remission. Progress in Neuro-psychopharmacology and Biological Psychiatry 31(7):1387-1392, 2007

58. Pandina G, et al.: Identification of clinically meaningful relationships among cognition, functionality, and symptoms in subjects with schizophrenia or schizoaffective disorder. Schizophrenia Research 143(2-3):312-318, 2013 
59. Fiedorowicz JG, et al.: Course of illness following prospectively observed mania or hypomania in individuals presenting with unipolar depression. Bipolar Disorder 14(6):664-671, 2012

60. Skokou M, Gourzis P: Demographic features and premorbid personality disorder traits in relation to age of onset and sex in paranoid schizophrenia. Psychiatry Research 215(3):554-559, 2014. doi:10.1016/j. psychres.2014.01.018

Malgorzata Maciukiewicz, PhD currently works as Postdoctoral Research Fellow at Centre for Addiction and Mental Health. Previously Dr Maciukiewicz worked Laboratory of Psychiatric Genetics in Poznan University of Medical Sciences. She was responsible for statistical computations design and conduct. Her present and past scientific interests are in a field of psychiatry genetics, especially pharmacogenetics and clinal dimensions of complex disorders. Dr. Maciukiewicz did her master studies, followed by immediate $\mathrm{PhD}$ studies, at Adam Mickiewicz University in Poznan in biology/bioinformatics.

Joanna Pawlak, PhD, MD is a physician, a specialist in psychiatry. She works in mental health center of Department of Psychiatry, University of Medical Sciences, Poznan. Her responsibility in Laboratory of Psychiatric Genetics was mainly the clinical design and realization of the project. Dr Pawlak did her PhD studies in the field of affective disorders and suicidology. She also participates in program of psychoeducation for bipolar patients.

Pawel Kapelski, PhD, MD is a physician, a specialist in psychiatry and works in mental health center of Department of Psychiatry, University of Medical Sciences, Poznan. His scientific interests are in a field of psychiatry genetics, mainly hereditary determinants of schizophrenia.

Magdalena Labędzka, MD is a physician and lawyer, $\mathrm{PhD}$ student in Laboratory of Psychiatric Genetics in Poznan University of Medical Sciences.

Maria Skibinska, $\mathbf{P h D}$ is a molecular biologist. Her PhD studies referred to genetics of schizophrenia. Her present scientific interests are in a field of gene expression in CNS and genetic data bases.

Dorota Zaremba is a pharmacist and laboratory diagnostician, PhD student in Laboratory of Psychiatric Genetics in Poznan University of Medical Sciences.

Anna Leszczynska-Rodziewicz, PhD, MD is a physician, a specialist in psychiatry and works in mental health center of Department of Psychiatry, University of Medical Sciences, Poznan. Her scientific interests are in a field of psychiatry genetics, mainly hereditary determinants of depression.

Monika Dmitrzak-Weglarz, PhD is a molecular biologist and laboratory diagnostician. Her PhD studies referred to genetics of anorexia. Her present and past scientific interests are in a field of psychiatry genetics and biostatistics, especially in eating disorders and neuropsychological markers.

Joanna Hauser, PhD, MD is a head of Laboratory of Psychiatric Genetics in Poznan University of Medical Sciences. She is a specialist in psychiatry and works in mental health center of Department of Psychiatry. $\mathrm{PhD}$ studies in medicine in 1982, postdoctoral degree in 1997. Prof. Hauser conducted substantial supervision on the study. 